\title{
Chinese Culture Communication in Teaching Chinese to Speakers of Other Languages

\author{
Yang ZHOU
} \\ College of International Education, Bohai University, Liaoning, China
}

\begin{abstract}
Keywords: Culture Communication; Chinese Culture; Teaching Chinese to Speakers of Other Languages (TCSOL).
\end{abstract}

\begin{abstract}
At present, Chinese study is developing rapidly all over the world at an unprecedented speed. A large number of foreigners are learning Chinese and committed to teach Chinese in their own countries. As we all know, language is the medium of cultural communication, and culture is the content of language expression. Therefore, the success of language teaching depends not only on language teaching itself, but also on cultural teaching. Moreover, the ultimate goal of language teaching is to enable learners to communicate appropriately on the basis of mastering language competence. Appropriate language communication needs to be based on the understanding of national cultural background. Learning Chinese is not only a language learning process, but also the collision and exchange between Chinese culture and other cultures of the world.
\end{abstract}

\section{The Role and Function of Cultural Communication in TCSOL}

\subsection{Cultural Communication Helps to Eliminate the Negative Impact of Cultural Differences}

According to the definition given by Hofstede, culture is the collective mental programming of the people in an environment conditioned by the same education and life experience. [3] People in different countries and regions have different educational and social backgrounds. Thus, they have different ways of thinking and different mental programming, and that is the source of culture differences, namely, culture conflicts. Therefore, in the process of teaching, TCSOL teachers should let students understand the differences between Chinese culture and their own cultures. Through the introduction of their own cultures, Chinese teachers can expound the unique different cultural phenomena and lead Chinese learners to understand the different ways of thinking of people in different cultural backgrounds, finally help them to eliminate the psychological disparity caused by culture differences.

\subsection{Cultural Communication Helps Students to Improve Learning Interest}

Chomsky states that language teaching is a process of cultural teaching. [2] Mr. Wang Zuoliang also pointed out that no one can really master language without understanding the social culture of the target language. [3] If the language learner intends to study a foreign language with no knowledge of the local culture, it will be difficult to have a successful communication under the circumstance that the learner has little culture knowledge of the target language. Culture communication in TCSOL will help language learners to deepen their impression and understanding of Chinese culture in various ways. Taking Chinese characters as an example: the characters have been inseparable from culture and many Chinese characters can read its rich cultural connotation from its shape. Through this way, language learners are able to cultivate their observation ability and further deepen their interest in learning.

\subsection{Cultural Communication Contributes to the Cultivation of Students' Intercultural Communicative Competence}

Intercultural communication takes language as the medium, which means that the communicators should abide by the cultural and pragmatic rules of the language and conform to the cultural background of the language. Language is an important tool for cultural communication and the use of language should also follow certain cultural conventions. Undoubtedly, each language has 
reflected the characteristics of a nation. It not only contains the historical and cultural background of the nation, but also embraces its life style and thinking mode. Therefore, learning a foreign language should not only emphasize on pronunciation, grammar, vocabulary and idioms, but also on how the language speakers look at things, how they observe the world, how they use their language to reflect the thoughts, habits and behaviors of their society, so that finally they can improve the communicative competence and overcome the communicative barriers caused by cultural differences.

\section{The Methods of Cultural Communication in TCSOL}

There are two methods of cultural communication in TCSOL: intralingual cultural elements and extralingual cultural elements.

\subsection{Intralingual Cultural Elements in TCSOL}

The underlying structure of a nation's cultural genes and cultural psychology is hidden in the national language. In Chinese language, the elements like words, vocabulary and grammar are all rich in Chinese cultural tradition.

\subsubsection{Cultural Elements in Phonetics Teaching}

The phonetic features of Chinese are characterized by well-defined syllables, well-organized formation and rhythmic sense, and this is widely used in Chinese poems and other literary rhyme. Moreover, Chinese has many homophones, and the homonyms therefrom become an important part of Chinese culture. For instance, " 4 " and " 8 " means death and fortune respectively in Chinese pronunciation. In a word, teachers can help learners by explaining the cultural elements in phonetics teaching in TCSOL.

\subsubsection{Cultural Elements in Chinese Character Teaching}

Chinese character is a cultural symbol which carries abundant historical and cultural information. As mentioned above, Chinese character is an ideographic character, which "embodies the traditional Chinese way of thinking and aesthetic concepts between both shape and meaning, pronunciation and meaning." [4] For example, the word "包" is like wrapping something up to form a nearly circular shape. This meaning is easy to see from the font. As we can see, Chinese learners associate many Chinese characters with radicals, it is an effective method for them to understand and memorize the characters and the meaning of the sentence. Chinese teachers should take full account of the characteristics of Chinese characters and explain them in the light of the historical background, cultural awareness and construction rules of Chinese characters in TCSOL.

\subsubsection{Cultural Elements in Vocabulary Teaching}

Vocabulary is the most intimate relation with the culture. There are many linguistic phenomena and semantic meanings of words in Chinese, which are often directly or indirectly related to specific cultural background. Through the lexical level of Chinese, we can see the state of Chinese culture and the cultural origin of vocabulary. The cultural factors in vocabulary teaching are mainly embodied in words and idioms. From the perspective of sociolinguistics, they bear the richest cultural content and are an important part of Chinese culture, which proves that only by understanding the cultural background of Chinese can we have the correct language communication.

\subsubsection{Cultural Elements in Grammar Teaching}

Chinese word order has a strong ability to express grammatical meaning, but different word order in some phrases also has certain cultural value orientation. The cultural values of the Chinese embodied in the Chinese word order should also be one of the important contents in our teaching. For example, the Chinese word order is based on "courtesy", which emphasizes the rank of the things, also the higher rank comes before the lower rank. [5] The combination between the rank and the order contributes to the harmony of the whole part and finally achieves "courtesy". We can see that the word order in Chinese is an obvious reflection of this value. Therefore, it is essential to 
teach the culture of "courtesy" in Chinese teaching process.

\subsection{Extralingual Cultural Elements in TCSOL}

According to a vote in the US Newsweek, the top three symbols representing China are Chinese, the Forbidden City of Beijing and the Great Wall. [6] This tells the teacher that, in Chinese teaching, teachers should introduce these linguistic elements embodying Chinese culture and explain cultural concepts in the form of cultural lessons, lectures and reports, so that more extralingual cultural elements can be understood by the learners.

\section{The Cultural Communication Strategy in TCSOL}

\subsection{The Culture Communication should be Focused on the Culture Similarities and Differences Step by Step}

While teaching Chinese as a foreign language, teachers should pay attention to Chinese traditional culture while teaching Chinese knowledge. China's traditional culture is extensive and profound; accordingly, it is quite complex and complicated. It often brings much study pressure as well as mental conflict for the language learner who has an entirely different cultural background. From this perspective, the Chinese teachers must master certain strategies in the process of culture communication. At the content level, teachers should focus on similarities and differences and follow proper sequence of steps. For example, the similarity between learners' culture background and Chinese culture is a good starting point for cultural communication, which helps to effectively avoid language learners' psychological conflict when they come into contact with new culture. After introducing and explaining on the basis of cultural similarities, teachers may search for a right time to introduce some classic features of the Chinese culture, and thus to stimulate learners' interest gradually.

\subsection{Culture Communication should Expand the Diversity and Shorten the Distance}

Based on different culture backgrounds, Chinese teachers should carry out various activities in culture communication and integrate culture into zero-distance contact activities, so as to make the learning process more vivid and interesting. It is not enough for language learners to obtain the culture essence merely through the introduction in the classroom. Therefore, for teachers, it is necessary to enrich and innovate the way of communication by all means, carry out face-to-face communication activities, or other extracurricular practical activities to tell learners about the ancient Chinese culture such as paper-cutting, shadow play, opera, etc. In fact, in the process of playing shadow games, learners can understand the artistic charm of the Chinese culture in a particular way. Only through their personal experience can they truly understand the value of traditional Chinese culture. By these activities, every Chinese learner can become a participant in the activities so that they maintain a zero-distance intimacy with Chinese culture in culture communication process.

\section{Conclusion}

With the increasing influence of Chinese on the world language stage, the culture communication needs more effective innovation to adapt to the fast changing and developing cultural trend. In the process of this study, we discussed some commonly used communication methods and strategies, and put forward some advice, we suggest that teachers should adhere to the principles of systematicness and objectivity, adopt diversified teaching approaches and methods, and meanwhile improve the pertinence of teaching. This paper is hoped to play a positive role in improving the level and quality of the Chinese culture communication in TCSOL.

\section{References}

[1] Geert Hofstede. Culture's Consequences [M]. SAGE Publications, Inc. 2003: 21. 
[2] Li Dongmei. Teaching Chinese as second language and the culture communication [J]. Language Teaching and Study. 2010 (3): 56

[3] Wang Zuoliang. Chinese and Foreign Literature [M]. Jiangsu: Jiangsu Education Publishing 1989: 220

[4] Youjing. Chinese teaching in intercultural communication [J]. Youth Literature, 2009 (7): 70.

[5] Liu Xun. Teaching Chinese as a Foreign Language [M]. Beijing: Beijing Language and Culture University Press, 2007: 112-114

[6] Zheng Huashu. Study on culture teaching to international students [D]. Dissertation for Heilongjiang University, 2011 